Military Technical College

Kobry Elkobbah,

Cairo, Egypt

May 27-29,2008

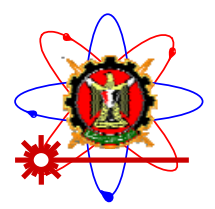

$4^{\text {th }}$ International Conference on

Mathematics and Engineering Physics (ICMEP-4)

EM-17

\title{
A GENERAL GOAL PROGRAMMING MODEL FOR SOLVING AGGREGATE PRODUCTION PLANNING PROBLEMS WITH IMPRECISE GOALS
}

\author{
MEZGHANI* M. LOUKIL** T. and DAMMAK ***A.
}

\begin{abstract}
Generally we assume that the decision-maker is able to give with precision and without difficulty, the values of the goals associated with the objectives of a decision-making situation. However, such values may be imprecise in nature. In the present paper, a general goal programming (GP) model was proposed to solve the aggregate production planning (APP) problem in an imprecise environment with multiple objectives. The goals and technological parameters are imprecise and expressed through intervals. The concept of satisfaction functions is used to integrate explicitly the decision maker's (DM) preferences.
\end{abstract}

\section{KEY WORDS:}

Aggregate Production Planning; Goal Programming; Satisfaction Functions; Imprecise goals and parameters.

\section{INTRODUCTION}

The Aggregate Production Planning (APP) problem consists in determining the optimum production, workforce, and inventory levels for each period of a planning horizon for a given set of production resources and constraints. Such planning usually involves one product or a family of similar products with small differences so that considering the problem from an aggregated viewpoint is justified. The objective is to meet the forecasted demand with the lowest cost. Typical costs related to APP include payroll, hiring/layoffs, overtime/undertime, and inventory shortage/backordering. Numerous APP models with varying degrees of complication (Holt et al. (1955), Bowman (1956), Hanssmann and Hess (1960), Baykasoglu (2001), Boppana and Slomp (2002), Silva et al. (2006), and Mezghani et al. (2008)) have been introduced in the last decades. However, the goals and model inputs (resources and demands) are generally assumed to be precise and deterministic. In real world APP problems, goals, technological parameters and coefficients are often imprecise or fuzzy because some information is incomplete or unavailable. Zimmermann (1976) first introduced fuzzy set theory into conventional LP problems. This study considered LP problems with a fuzzy goal and fuzzy constraints. Following the fuzzy decision making method proposed by Bellman and Zadeh (1970) and using linear membership functions, the above study confirmed the existence of an equivalent LP problem. Thereafter, fuzzy mathematical programming has developed with to solve APP problems. Lee (1993) presented an interactive fuzzy linear programming model to solve APP problems. The model only considered situations with soft constraints and single objective function for total cost. Wang and Liang (2004) developed a fuzzy multi 
Proceeding of $4^{\text {th }}$ International Conference on Engineering Mathematics and Physics

objective linear programming model with the piecewise linear membership function to solve multi product APP decision problems in a fuzzy environment. The model can yield an efficient compromise solution and the decision maker's overall levels of satisfaction. Additional fuzzy APP problem solving studies include Gen et al. (1992), Tang et al. (2000), and Wang and Fung (2001). Recently, Wang and Liang (2005) developed a novel interactive possibilistic linear programming approach for solving the multi-product APP decision problem where cost coefficients in the objective function, forecast demand, and capacity are imprecise. This approach attempts to minimize the total cost which is the sum of the production costs and the costs of changes in labor levels over the planning horizon.

We observe that, almost the majority of the suggested approaches for the production planning problems do not explicitly integrate the decision maker's preferences. In this paper, we develop a GP model for APP problem in an imprecise environment where the structure of the decision-maker's preferences is explicitly considered by utilizing the concept of satisfaction functions introduced by Martel and Aouni (1990, 1998).

The paper is organised as follows. In section 2, we present a general GP model where the goals and technological parameters are imprecise. In section 3, we present the concept of satisfaction function. The general model is reformulated by using the concept of satisfaction functions in section 4. In section 5, we describe the APP problem, notation and we formulate this problem when the DM's preferences are explicitly integrated. Conclusion is finally drawn in section 6 .

\section{THE GP MODEL IN AN IMPRECISE ENVIRONMENT}

A GP model in an imprecise environment is defined as follows:

Program 1

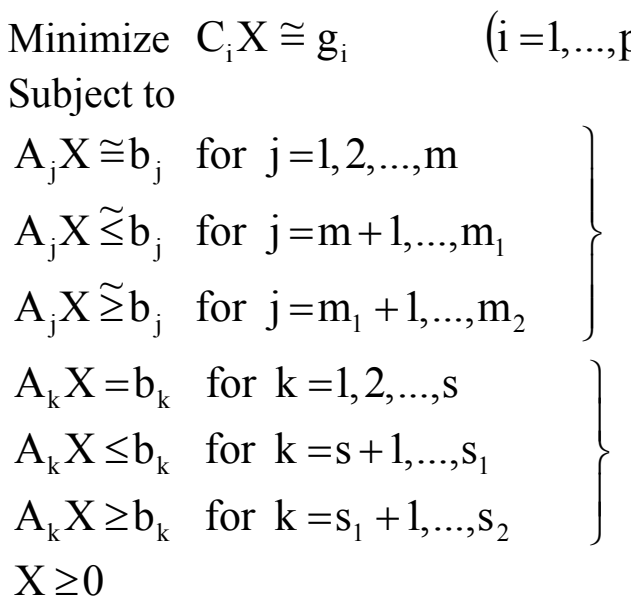

Where $\mathrm{X}$ denotes an $\mathrm{n}$-dimensional vector of the decision variables, $\mathrm{A}_{\mathrm{j}}$ and $\mathrm{C}_{\mathrm{i}}$ are vectors of coefficients, $g_{\mathrm{i}}$ are the target values (the goals) given by the decision maker, $\mathrm{b}_{\mathrm{j}}$ are fuzzy right-hand sides of $\mathrm{j}^{\text {th }}$ constraints and $\mathrm{b}_{\mathrm{k}}$ are precise right hand sides of $\mathrm{k}^{\text {th }}$ constraints.

The objective function symbol $\cong$ is the fuzzified version of $=$ and refers to the imprecise nature of the aspiration levels. In real-world APP decision problems, technological parameters and coefficients are uncertain, because some information is incomplete or unavailable in a medium term horizon. Accordingly, constraints (1) are imprecise in nature and flexible and may be violated. Constraints (2) are crisp. The flexible constraints can be considered as goals. 
Let us denote the deviations from the goal values:

$$
\begin{array}{ll}
\delta_{i}^{+}=\max \left\{C_{i} X-g_{i}, 0\right\}, \delta_{i}^{-}=\max \left\{g_{\mathrm{i}}-\mathrm{C}_{\mathrm{i}} \mathrm{X}, 0\right\} & \text { for } \mathrm{i}=1,2, \ldots, \mathrm{p} \\
\rho_{\mathrm{j}}^{+}=\max \left\{\mathrm{A}_{\mathrm{j}} \mathrm{X}-\mathrm{b}_{\mathrm{j}}, 0\right\}, \rho_{\mathrm{j}}^{-}=\max \left\{\mathrm{b}_{\mathrm{j}}-\mathrm{A}_{\mathrm{j}} \mathrm{X}, 0\right\} & \text { for } \mathrm{j}=1,2, \ldots \mathrm{m} \\
\gamma_{\mathrm{j}}^{+}=\max \left\{\mathrm{A}_{\mathrm{j}} \mathrm{X}-\mathrm{b}_{\mathrm{j}}, 0\right\}, \gamma_{\mathrm{j}}^{-}=\max \left\{\mathrm{b}_{\mathrm{j}}-\mathrm{A}_{\mathrm{j}} \mathrm{X}, 0\right\} & \text { for } \mathrm{j}=\mathrm{m}+1, \ldots, \mathrm{m}_{1} \\
\chi_{\mathrm{j}}^{+}=\max \left\{\mathrm{A}_{\mathrm{j}} \mathrm{X}-\mathrm{b}_{\mathrm{j}}, 0\right\}, \chi_{\mathrm{j}}^{-}=\max \left\{\mathrm{b}_{\mathrm{j}}-\mathrm{A}_{\mathrm{j}} \mathrm{X}, 0\right\} & \text { for } \mathrm{j}=\mathrm{m}_{1}+1, \ldots \mathrm{m}_{2}
\end{array}
$$

$\delta_{\mathrm{i}}^{+}, \rho_{\mathrm{i}}^{+}, \gamma_{\mathrm{j}}^{+}$and $\chi_{\mathrm{j}}^{+}$: Over achievement of the goals $\mathrm{g}_{\mathrm{i}}$ and $\mathrm{b}_{\mathrm{j}}$ respectively

$\delta_{i}^{-}, \rho_{i}^{-}, \gamma_{j}^{-}$and $\chi_{j}^{-}$: Under achievement of the goals $g_{i}$ and $b_{j}$ respectively

In all the types of goals, we admit all of them, but some of them are undesired:

- For $\mathrm{i}=1, \ldots, \mathrm{P}$ both $\delta_{\mathrm{i}}^{+}$and $\delta_{\mathrm{i}}^{-}$are undesired

- For $j=1, \ldots, m$ both $\rho_{\mathrm{i}}^{+}$and $\rho_{\mathrm{i}}^{-}$are undesired

- For $\mathrm{j}=\mathrm{m}+1, \ldots, \mathrm{m}_{1} \gamma_{\mathrm{j}}^{+}$are undesired

- For $\mathrm{j}=\mathrm{m}_{1}+1, \ldots, \mathrm{m}_{2} \quad \chi_{\mathrm{j}}^{-}$are undesired

The objective is to minimize the sum of undesired deviations from those goals. In the following section, we present the concept of satisfaction functions. This concept was introduced into the goal programming model to take into account the decision-maker's preferences.

\section{THE CONCEPT OF SATISFACTION FUNCTIONS}

The GP, which is an extension of the linear programming, is an easy method to understand and use. First, developed by Charnes and Cooper (1961), this method knew a great popularity (Aouni, 1988; Aouni and Kettani, 2001; Martel and Aouni, 1990, 1998) and it has been applied in many diversified fields, such as: the management of the hydraulic basins, the solid waste management, human resources, production,... Regarding methodological development, we note three extensions to the GP model that deal with the imprecision and the fuzziness of the goal values, namely: the fuzzy GP (FGP), the GP with intervals (GPI) and the GP with satisfaction functions. The FGP and GPI formulations deal with situations where the membership function (FGP) and the penalty function (GPI) are linear and symmetric. In addition, these functions favour the central value of the goal deviations. These models put more emphasis on the imprecision of the goals and less on DM's preferences modelling. To remedy these shortcomings, Martel and Aouni (1990) introduced the concept of satisfaction functions that allow the DM to express his/her preferences for different achievement levels of each objective. The satisfaction functions are not necessarily linear and symmetric as the case of membership function and the penalty function used respectively in FGP and GPI. The general form of the satisfaction function is shown in Fig.1.

Through the satisfaction functions the decision-maker has the possibility to introduce explicitly his/her preferences, can modify, at any time, the satisfaction functions. The objective function of the GP model can be rewritten in the following form:

$\underset{x \in X}{\operatorname{Maximize}} Z=\sum_{i=1}^{p} w_{i}\left(F_{i}^{+}\left(\delta_{i}^{+}\right)+F_{i}^{-}\left(\delta_{i}^{-}\right)\right)$

Where: $\delta_{i}^{+}$and $\delta_{i}^{-}$are positive and negative deviations from the goal $\mathrm{i} ; w_{i}$ expresses the relative importance of the goal $\mathrm{i}$. 
Proceeding of $4^{\text {th }}$ International Conference on Engineering Mathematics and Physics

S-EM III 138

In the following section, we use the concept of the satisfaction functions for modelling the imprecise goals and technological parameters in the GP model to explicitly integrate the decision maker's preferences.

\section{REFORMULATING THE IMPRECISE GP THROUGH THE SATISFACTION FUNCTION}

To explicitly model the decision maker's preferences in an imprecise environment, two limits are fixed, the upper limits $\left(\bar{g}_{\mathrm{i}}\right)$ and $\left(\overline{\mathrm{b}}_{\mathrm{j}}\right)$ and the lower limits $\left(\underline{\mathrm{g}}_{\mathrm{i}}\right)$ and $\left(\underline{\mathrm{b}}_{\mathrm{j}}\right)$. The fuzzy values (aspiration levels) specified by the decision maker $\widetilde{g}_{i}$ et $\widetilde{b}_{j}$ can also be arbitrarily chosen from intervals. So $\widetilde{g}_{i} \in\left\lfloor\underline{g}_{i}, \bar{g}_{i}\right\rfloor$ and $\widetilde{b}_{j} \in\left\lfloor\underline{b}_{j}, \bar{b}_{j}\right\rfloor$.

By introducing the satisfaction function, presented earlier, Program 1 may be formulated as follows:

Program 2

$\operatorname{Maximize} \sum_{\mathrm{i}=1}^{\mathrm{p}} \mathrm{w}_{\mathrm{i}}\left(\mathrm{F}_{\mathrm{i}}^{+}\left(\delta_{\mathrm{i}}^{+}\right)+\mathrm{F}_{\mathrm{i}}^{-}\left(\delta_{\mathrm{i}}^{-}\right)\right)+\sum_{\mathrm{j}=1}^{\mathrm{m}} \mathrm{w}_{\mathrm{j}}\left(\mathrm{F}_{\mathrm{j}}^{+}\left(\rho_{\mathrm{j}}^{+}\right)+\mathrm{F}_{\mathrm{j}}^{-}\left(\rho_{\mathrm{j}}^{-}\right)\right)+\sum_{\mathrm{j}=\mathrm{m}+1}^{\mathrm{m}_{1}} \mathrm{w}_{\mathrm{j}} \mathrm{F}_{\mathrm{j}}^{+}\left(\gamma_{\mathrm{j}}^{+}\right)+\sum_{\mathrm{j}=\mathrm{m}_{1}+1}^{\mathrm{m}_{2}} \mathrm{w}_{\mathrm{j}} \mathrm{F}_{\mathrm{j}}^{-}\left(\chi_{\mathrm{j}}^{-}\right)$

Subject to

$$
\begin{array}{ll}
\mathrm{C}_{\mathrm{i}} \mathrm{X}-\delta_{\mathrm{i}}^{+}+\delta_{\mathrm{i}}^{-}=\widetilde{\mathrm{g}}_{\mathrm{i}} & (\mathrm{i}=1, \ldots, \mathrm{p}) \\
\mathrm{A}_{\mathrm{j}} \mathrm{X}-\rho_{\mathrm{j}}^{+}+\rho_{\mathrm{j}}^{-}=\widetilde{\mathrm{b}}_{\mathrm{j}} & (\mathrm{j}=1, \ldots, \mathrm{m}) \\
\mathrm{A}_{\mathrm{j}} \mathrm{X}-\gamma_{\mathrm{j}}^{+}+\gamma_{\mathrm{j}}^{-}=\widetilde{\mathrm{b}}_{\mathrm{j}} & \left(\mathrm{j}=\mathrm{m}+1, \ldots, \mathrm{m}_{1}\right) \\
\mathrm{A}_{\mathrm{j}} \mathrm{X}-\chi_{\mathrm{j}}^{+}+\chi_{\mathrm{j}}^{-}=\widetilde{\mathrm{b}}_{\mathrm{j}} & \left(\mathrm{j}=\mathrm{m}_{1}+1, \ldots, \mathrm{m}_{2}\right) \\
\mathrm{A}_{\mathrm{k}} \mathrm{X}=\mathrm{b}_{\mathrm{k}} & (\mathrm{k}=1, \ldots, s) \\
\mathrm{A}_{\mathrm{k}} \mathrm{X} \leq \mathrm{b}_{\mathrm{k}} & \left(\mathrm{k}=\mathrm{s}+1, \ldots, \mathrm{s}_{1}\right) \\
\mathrm{A}_{\mathrm{k}} \mathrm{X} \geq \mathrm{b}_{\mathrm{k}} & \left(\mathrm{k}=\mathrm{s}_{1}+1, \ldots, \mathrm{s}_{2}\right) \\
\mathrm{X} \geq 0 & \\
\delta_{\mathrm{i}}^{+} \text {and } \delta_{\mathrm{i}}^{-} \leq \alpha_{\mathrm{iv}} & \\
\rho_{\mathrm{j}}^{+} \text {and } \rho_{\mathrm{j}}^{-} \leq \alpha_{\mathrm{jv}} & \\
\gamma_{\mathrm{i}}^{+} \text {and } \gamma_{\mathrm{i}}^{-} \leq \alpha_{\mathrm{jv}} & \\
\chi_{\mathrm{j}}^{+} \text {and } \chi_{\mathrm{j}}^{-} \leq \alpha_{\mathrm{jv}} & \\
\delta_{\mathrm{i}}^{+}, \rho_{\mathrm{j}}^{+}, \gamma_{\mathrm{j}}^{+} \text {and } \chi_{\mathrm{j}}^{+} \geq 0, \delta_{\mathrm{i}}^{-}, \rho_{\mathrm{j}}^{-}, \gamma_{\mathrm{j}}^{-} \text {and } \chi_{\mathrm{j}}^{-} \geq 0 .
\end{array}
$$

In the following, we use this proposed GP model to develop a new formulation that explicitly integrate the DM's preferences for aggregate production planning in an imprecise environment.

\section{APP MODEL DEVELOPMENT}

\section{1 problem description and notation}

Assume that a company manufactures $\mathrm{N}$ types of products to satisfy the market demand over a planning horizon T. Generally, the technological coefficients and parameters are uncertain 
in a medium term horizon. Therefore, the forecasted demand, maximum number of workers and machine capacity are imprecise over the planning horizon.

Two objectives are considered in this APP decision problem:

1) Minimize total production costs

The total production costs include four components, regular time production $\operatorname{costs} \sum_{\mathrm{n}=1}^{\mathrm{N}} \sum_{\mathrm{t}=1}^{\mathrm{T}} \mathrm{CP}_{\mathrm{nt}} \cdot \mathrm{P}_{\mathrm{nt}}$, overtime production $\quad$ costs $\sum_{\mathrm{n}=1}^{\mathrm{N}} \sum_{\mathrm{t}=1}^{\mathrm{T}} \mathrm{CO}_{\mathrm{nt}} \cdot \mathrm{O}_{\mathrm{nt}}$, subcontracting $\operatorname{costs} \sum_{n=1}^{N} \sum_{t=1}^{T} C S_{n t} . S_{n t}$ and the inventory costs $\sum_{\mathrm{n}=1}^{\mathrm{N}} \sum_{\mathrm{t}=1}^{\mathrm{T}} \mathrm{CI}_{\mathrm{nt}} . \mathrm{I}_{\mathrm{nt}}$. The objective function is as follows:

$$
\operatorname{Minimize} \widetilde{Z}_{1}=\sum_{n=1}^{N} \sum_{t=1}^{T}\left(C P_{n t} \cdot P_{n t}+C O_{n t} \cdot O_{n t}+C S_{n t} \cdot S_{n t}+C I_{n t} \cdot I_{n t}\right)
$$

2) Minimize the changes in workforce levels

This objective includes the costs of hiring $\sum_{t=1}^{T} C H_{t} \cdot H_{t}$ and the costs of layoff $\sum_{t=1}^{T} C F_{t} . F_{t}$. The objective function is as follow:

$$
\text { Minimize } \widetilde{Z}_{2}=\sum_{t=1}^{T}\left(C H_{t} \cdot H_{t}+C F_{t} \cdot F_{t}\right)
$$

The following notation is used

$\widetilde{D}_{n t}$ : Forecasted demand of product $\mathrm{n}$ in period $\mathrm{t}$;

$\mathrm{W}_{\mathrm{t}}$ : Workforce level in period $\mathrm{t}$;

$C P_{n t}$ : Production cost per unit of regular time for product $\mathrm{n}$ in period $\mathrm{t}$;

$P_{n t}$ : Regular time production of product $\mathrm{n}$ in period $\mathrm{t}$;

$\mathrm{CO}_{n t}$ : Production cost per unit of overtime for product $\mathrm{n}$ in period $\mathrm{t}$;

$\mathrm{O}_{\mathrm{nt}}$ : Overtime production of product $\mathrm{n}$ in period $\mathrm{t}$;

$C S_{n t}$ : Cost to subcontract one unit of product $\mathrm{n}$ for one period;

$S_{n t}$ : Subcontracted production of product $\mathrm{n}$ in period $\mathrm{t}$;

$C I_{n t}$ : Inventory cost per unit for product $\mathrm{n}$ in period $\mathrm{t}$;

$I_{n t}$ : Inventory of product $\mathrm{n}$ at the beginning of period $\mathrm{t}$;

$\mathrm{CH}_{t}$ : Cost to hire one worker in period $\mathrm{t}$;

$H_{t}$ : Number of workers hired in period $\mathrm{t}$;

$C F_{t}$ : Cost to layoff one worker in period $\mathrm{t}$;

$F_{t}$ : Number of workers laid off in period $\mathrm{t}$;

$i_{n t}$ : Labor time for product $\mathrm{n}$ in period $\mathrm{t}$ (man hour/unit);

$r_{n t}$ : Machine hours per unit of product $\mathrm{n}$ in period $\mathrm{t}$ (machine hour/unit);

$\widetilde{W}_{t \max }:$ Maximum workforce available in period t;

$\widetilde{M}_{t \max }$ : Maximum machine capacity available in period $\mathrm{t}$; (machine-hour);

a : Regular working hours per worker;

$b_{t}$ : Fraction of working hours available for overtime production. 
The constraints:

- Inventory level constraints

$$
\mathrm{I}_{\mathrm{nt}-1}+\mathrm{P}_{\mathrm{nt}}+\mathrm{O}_{\mathrm{nt}}+\mathrm{S}_{\mathrm{nt}}-\mathrm{I}_{\mathrm{nt}}=\widetilde{\mathrm{D}}_{\mathrm{nt}} \quad(\mathrm{n}=1, \ldots, \mathrm{N}),(\mathrm{t}=1, \ldots, \mathrm{T})
$$

- Workforce constraints

$$
\begin{array}{cr}
\mathrm{W}_{\mathrm{t}}=\mathrm{W}_{\mathrm{t}-1}+\mathrm{H}_{\mathrm{t}}-\mathrm{F}_{\mathrm{t}} & (\mathrm{t}=1, \ldots, \mathrm{T}) \\
\mathrm{W}_{\mathrm{t}} \leq \widetilde{\mathrm{W}}_{\mathrm{t} \max } & (\mathrm{t}=1, \ldots, \mathrm{T}) \\
\sum_{\mathrm{n}=1}^{\mathrm{N}} \mathrm{i}_{\mathrm{nt}} \mathrm{P}_{\mathrm{nt}} \leq \mathrm{a} \mathrm{W}_{\mathrm{t}} & (\mathrm{t}=1, \ldots, \mathrm{T}) \\
\sum_{\mathrm{n}=1}^{\mathrm{N}} \mathrm{i}_{\mathrm{nt}} \mathrm{O}_{\mathrm{nt}} \leq \mathrm{ab} \mathrm{b}_{\mathrm{t}} \mathrm{W}_{\mathrm{t}} & (\mathrm{t}=1, \ldots, \mathrm{T})
\end{array}
$$

- Machine capacity contraints

$$
\sum_{\mathrm{n}=1}^{\mathrm{N}} \mathrm{r}_{\mathrm{nt}}\left(\mathrm{P}_{\mathrm{nt}}+\mathrm{O}_{\mathrm{nt}}\right) \leq \tilde{\mathrm{M}}_{\mathrm{t} \max } \quad(\mathrm{t}=1, \ldots, \mathrm{T})
$$

- Non- négativity contraints

$$
\mathrm{W}_{\mathrm{t}}, P_{n t}, \mathrm{O}_{\mathrm{nt}}, S_{n t}, I_{n t}, H_{t}, F_{t} \geq 0 \quad(\mathrm{n}=1,2, \ldots, \mathrm{N}),(\mathrm{t}=1,2, \ldots, \mathrm{T}) .
$$

The forecasted demand $\widetilde{D}_{n t}$ of product $\mathrm{i}$ in period $\mathrm{t}$ is imprecise. In real world APP decision problems, the forecasted demand cannot be obtained precisely in a dynamic market. The sum of regular and overtime production, inventory levels, and subcontracting levels essentially should be equal to the market demand, as in equation (1). Moreover, the maximum workforce available (3) and the maximum available machine capacity (6) are imprecise. Constraints (2), (4) and (5) are crisp.

\subsection{APP model with satisfaction function}

We suppose that $\mathrm{N}=1$ and $\mathrm{T}=6$. The objective is to elaborate an aggregate production plan where the DM's preferences are explicitly integrated in an imprecise environment. The objective function which maximizes the DM satisfaction is as follow:

Program 3

Maximize $Z=\sum_{i=1}^{2} w_{i}\left(F_{i}^{+}\left(\delta_{i}^{+}\right)+F_{i}^{-}\left(\delta_{i}^{-}\right)\right)+\sum_{j=1}^{6} w_{j}\left(F_{j}^{+}\left(\rho_{j}^{+}\right)+F_{j}^{-}\left(\rho_{j}^{-}\right)\right)+\sum_{j=7}^{18} w_{j} F_{j}^{+}\left(\gamma_{j}^{+}\right)$

\section{Contraints model :}

Goal constraint $\widetilde{Z}_{1}$

$$
\sum_{\mathrm{t}=1}^{6}\left(\mathrm{CP}_{\mathrm{t}} \cdot \mathrm{P}_{\mathrm{t}}+\mathrm{CO}_{\mathrm{t}} \cdot \mathrm{O}_{\mathrm{t}}+\mathrm{CS}_{\mathrm{t}} \cdot \mathrm{S}_{\mathrm{t}}+\mathrm{CI}_{\mathrm{t}} \cdot \mathrm{I}_{\mathrm{t}}\right)-\delta_{1}^{+}+\delta_{1}^{-}=\widetilde{\mathrm{Z}}_{1}
$$

Goal constraint $\widetilde{Z}_{2}$ 


$$
\sum_{t=1}^{6}\left(C H_{t} \cdot H_{t}+C F_{t} \cdot F_{t}\right)-\delta_{2}^{+}+\delta_{2}^{-}=\widetilde{Z}_{2}
$$

Inventory level constraints

$$
\mathrm{I}_{\mathrm{t}-1}+\mathrm{P}_{\mathrm{t}}+\mathrm{O}_{\mathrm{t}}+\mathrm{S}_{\mathrm{t}}-\mathrm{I}_{\mathrm{t}}-\rho_{\mathrm{j}}^{+}+\rho_{\mathrm{j}}^{-}=\widetilde{\mathrm{D}}_{\mathrm{t}} \quad \text { for }(\mathrm{j}=1, \ldots, 6)
$$

Workforce constraints

$$
\mathrm{W}_{\mathrm{t}}-\gamma_{\mathrm{j}}^{+}+\gamma_{\mathrm{j}}^{-}=\widetilde{\mathrm{W}}_{\mathrm{t} \max }
$$

Machine capacity contraints

$$
\mathrm{r}_{\mathrm{t}}\left(\mathrm{P}_{\mathrm{t}}+\mathrm{O}_{\mathrm{t}}\right)-\gamma_{\mathrm{j}}^{+}+\gamma_{\mathrm{j}}^{-}=\tilde{\mathrm{M}}_{\mathrm{t} \max }
$$

Rigid constraints

$$
\begin{gathered}
\mathrm{W}_{\mathrm{t}}=\mathrm{W}_{\mathrm{t}-1}+\mathrm{H}_{\mathrm{t}}-\mathrm{F}_{\mathrm{t}} \\
\mathrm{i}_{\mathrm{t}} \mathrm{P}_{\mathrm{t}} \leq \mathrm{aW} \mathrm{W}_{\mathrm{t}}
\end{gathered}
$$$$
\mathrm{i}_{\mathrm{t}} \mathrm{O}_{\mathrm{t}} \leq \mathrm{ab}_{\mathrm{t}} \mathrm{W}_{\mathrm{t}}
$$$$
\delta_{\mathrm{i}}^{+} \text {and } \delta_{\mathrm{i}}^{-} \leq \alpha_{\mathrm{iv}}
$$$$
\text { for }(i=1,2)
$$

$\rho_{\mathrm{j}}^{+}$and $\rho_{\mathrm{j}}^{-} \leq \alpha_{\mathrm{jv}}$

$$
\text { for }(j=1, \ldots, 6)
$$

$\gamma_{\mathrm{j}}^{+}$and $\gamma_{\mathrm{j}}^{-} \leq \alpha_{\mathrm{jv}}$

$\delta_{\mathrm{i}}^{+}, \rho_{\mathrm{j}}^{+}$and $\gamma_{\mathrm{j}}^{+} \geq 0, \delta_{\mathrm{i}}^{-}, \rho_{\mathrm{j}}^{-}$and $\gamma_{\mathrm{j}}^{-} \geq 0$.

\section{NUMERICAL EXAMPLE}

To illustrate the proposed model, a simple APP problem with imprecise goals is solved. The parameters used are as follows:

(1) There is a six period planning horizon with deterministic demands of 200, 180, 250, 280, 250, and 300 units for periods 1 to 6 respectively.

(2) The total production costs and the changes in workforce levels are imprecise and the permissible limits are 58000-62000 and 80-120 respectively.

(3) Overtime production is limited to no more than $14 \%$ of regular time production. The overtime cost is $49 \mathrm{MU}$ (Monetary Unit) per unit.

(4) The initial inventory $\left(I_{0}\right)$ is null. The inventory carrying cost is 2 MU per unit per period.

(5) The initial workforce $\left(\mathrm{W}_{0}\right)$ is 100 (man-day). The costs associated with the regular payroll, hiring and firing are respectively $60 \mathrm{MU}, 30 \mathrm{MU}$, and $40 \mathrm{MU}$ (MU/man-day) per worker.

(6) The production cost is 16 MU per unit. 3 hours of labor are needed for each unit produced. The regular time per worker is 8 hours.

For the illustration purposes we use a satisfaction function with linear preference type (Martel and Aouni, 1990). The shape of this function is presented in Fig. 2. The relative importance coefficients associated to the two considered objectives are equal. The satisfaction function thresholds are given in Table 1.

For the two objectives we have a tendency towards the lower bound of the target intervals. The satisfaction functions were used to incorporate explicitly the decision-maker's preferences in an imprecise environment. The equivalent representation of the different satisfaction functions requires introducing some binary variables. The obtained model is nonlinear. The linearization procedure developed by Oral and Kettani (1992) is used to obtain the linear equivalent (Mezghani et al. 2008). The software Lindo package is used to solve the mathematical program. The obtained solution is shown as follows:

$P_{t}=[200,216,261,261,261,261]$ 
$\mathrm{O}_{\mathrm{t}}=[0,0,0,0,0,0]$

$\mathrm{W}_{\mathrm{t}}=[98,98,98,98,98,98]$

$\mathrm{I}_{\mathrm{t}}=[0,36,47,28,39,0]$

The satisfaction level of the objective function is about $85 \%$. The goals attained are: $Z_{1}=58940$, and $Z_{2}=80$.

\section{CONCLUSION}

To deal with the imprecise nature of data in aggregate production planning, we developed a GP model based on the concept of satisfaction functions. We proposed a general model that integrates the DM's preferences where the goals and technological parameters are imprecise and expressed through intervals. The decision-maker made up of few thresholds which have a concrete significance for him. The proposed approach in this model allows the decision-maker to act, at any moment, on the results or on the proposed choices made by the mathematical model and to revise, if necessary the thresholds of his satisfaction functions in order to insure that they reflect his preferences in the best possible way and his perception of the imprecise information. We have illustrated our proposed model on a simple numerical example.

\section{REFERENCES}

[1] Aouni, B. "Introduction of the preferences of the decision maker by the model of Goal Programming: A new formulation and application", Thesis, Faculty of Science of the Administration, Laval University, pp. 62-94, (1988).

[2] Aouni, B. and Kettani, O. "Goal programming model: With glorious history and has promising future", European Journal of Operational Research, Vol.133, pp. 225-231, (2001).

[3] Bowman, E.H. "Production scheduling by the transportation method of linear programming", Operations Research, Vol. 4, No. 1, pp.100-103, (1956).

[4] Bellman, R.E. and Zadeh L.A. "Decision making in a fuzzy environment", Management Science, Vol. 17, pp. 141-164, (1970).

[5] Baykasoglu, A. MOAPPS 1.0: "Aggregate production planning using the multiple objectives tabu search". International Journal of Production Research, Vol. 39, pp.3685-3702, (2001).

[6] Boppana, V.C. and Slomp, J. "Production planning under Dynamic Product Environment: A Multi-objective Goal Programming Approach", Research report, $\mathrm{N}^{\circ} 02 \mathrm{~A} 12$, University of Groningen, (2002).

[7] Charnes, A. and Cooper, W.W. "Management models and industrial applications of linear programming", Wiley, New York, (1961).

[8] Gen, M, Tsujimura, Y. and Ida, K. "Method for solving multi objective aggregate production planning problem with fuzzy parameters", Computers and Industrial Engineering, Vol.23, pp. 117-120, (1992). 
Proceeding of $4^{\text {th }}$ International Conference on Engineering Mathematics and Physics

[9] Holt, D.C., Modigliani F. and Simon, H.A. "A linear decision rule for production and employment scheduling”, Management Science, Vol. 12, pp. 1-30, (1955).

[10] Hanssmann, F. and Hess, S.U., "A linear programming approach to production and employment scheduling”, Management Technology, Vol.1, pp. 46-54, (1960).

[11] Lee, Y.Y. "A fuzzy linear programming approach to aggregate production planning", Journal of the Chinese Institute of Industrial Engineers, Vol. 10, pp. 25-32, (1993).

[12] Martel, J.M. and Aouni, B. "Incorporating the decision-maker's preferences in the goal programming model", Journal of Operational Research Society, Vol. 41, No.12, pp. 11211132, (1990).

[13] Martel, J.M. and Aouni, B. "Diverse imprecise goal programming model formulations", Journal of global Optimization, Vol.12, pp. 127-138, (1998).

[14] Mezghani, M., Rebai, A., Dammak, A. and Loukil, T. "A goal programming model for aggregate production planning problem", International Journal of Operational Research, in press, (2008).

[15] Oral, Mr. and Kettani, O. "A Linearization Procedure for Quadratic and Cubic MixedInteger Problems", Operations Research, Vol. 40, No.1, pp.109-116, (1992).

[16] Silva, C.G. da, Figueira, J., Lisboa J. and Barman, S. "An interactive decision support system for an aggregate production planning model based on multiple criteria mixed integer linear programming", The International Journal of Management Science, Omega, Vol. 34, pp. 167-177, (2006).

[17] Tang, J., Wang, D. and Fung, R.Y.K "Fuzzy formulation for multi-product aggregate production planning", Production Planning and Control, Vol. 11, pp. 670-676, (2000).

[18] Wang, R.C, Fang, H.H. "Aggregate production planning with multiple objectives in a fuzzy environment", European Journal of Operational Research, Vol.133, pp. 521-536, (2001).

[19] Wang, R.C, Liang, T.F. "Application of fuzzy multi objective linear programming environment to aggregate production planning", Computers and Industrial Engineering, Vol.46 No. 1, pp. 17-41, (2004).

[20] Wang, R.C, Liang, T.F. "Applying possibilistic linear programming to aggregate production planning", International Journal of Production Economics, Vol. 98, pp.328-341, (2005).

[21] Zimmermann, H.J. "Description and optimization of fuzzy systems", International Journal of General Systems, Vol. 2, pp.209-215, (1982). 


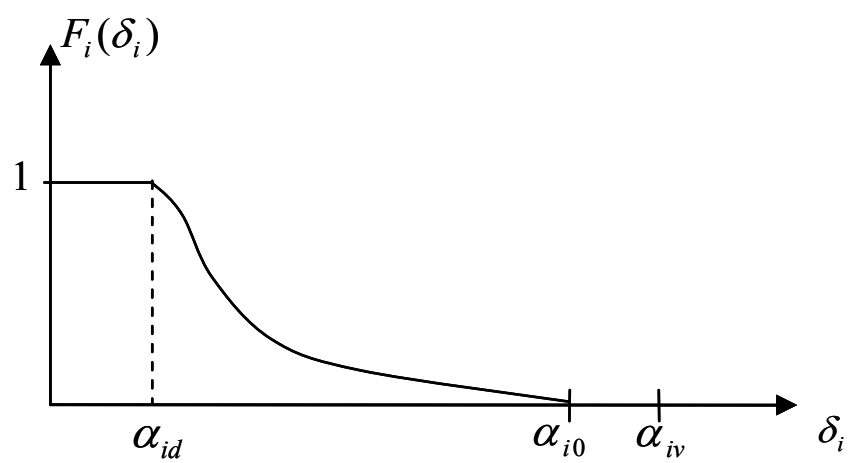

Fig.1. General form of the satisfaction function: $F_{i}\left(\delta_{i}\right)$ is the satisfaction function associated with deviations $\delta_{i}, \alpha_{i d}$ is the indifference threshold; $\alpha_{i 0}$ is the null satisfaction threshold and $\alpha_{i v}$ is the veto threshold.

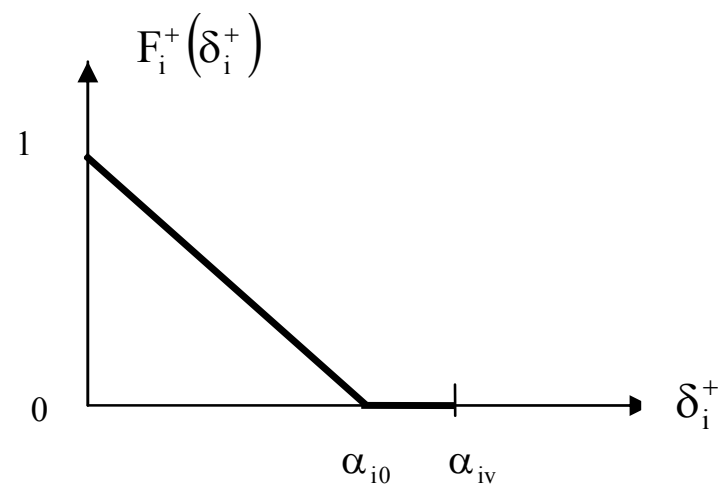

Fig.2. The used satisfaction function

Table 1. Satisfaction thresholds

\begin{tabular}{|c|c|c|}
\hline Objectives & Nil-satisfaction threshold & Veto threshold \\
\hline Total production costs & 3000 & 4000 \\
\hline The changes in workforce levels & 30 & 40 \\
\hline
\end{tabular}

